\title{
O ESTABELECIMENTO DE NÍVEIS DE COMPETÊNCIA EM TRADUÇÃO: PRIMEIROS RESULTADOS DO PROJETO NACT ${ }^{1}$
}

\author{
Grupo PACTE: \\ Amparo Hurtado Albir 1 \\ Anabel Galán-Mañas 1 \\ Christian Olalla-Soler 1 \\ Patricia Rodríguez-Inés $\underline{1}$ \\ Lupe Romero 1 \\ IUniversidade Autônoma de Barcelona, Barcelona, Espanha
}

Anna Kuznik 2

²Uniwersytet Wrocławski, Breslávia, Polonia

Tradução de Talita Serpa ${ }^{3}$

-3Universidade Estadual Paulista “Júlio de Mesquita Filho", São José do Rio

Preto, São Paulo, Brasil

Resumo: Este artigo tenciona apresentar o projeto de pesquisa realizado pelo grupo PACTE acerca da proposta de um Nivelamento de Competências na Aquisição da Competência Tradutória (tradução escrita). O objetivo do projeto é preparar uma proposta de descritores de nível, a qual se configura como um primeiro passo para desenvolver um Quadro Europeu

1 A presente tradução foi autorizada para ser publicada em português pelo diretor da Revista, Carlos González Vergara, e pelos respectivos autores. In: PACTE. "Establecimiento de niveles decompetencias en traducción. Primeros resultados del proyecto NACT". Onomázein: Revista de lingüística, filología y traducción de la Pontificia Universidad Católica de Chile. 43, (2019): $1-25$. 
Comum de Referência nos campos acadêmico e profissional da tradução. Trata-se de uma continuação da pesquisa experimental do PACTE sobre competência em tradução e aquisição de competências tradutórias. Representantes do mundo acadêmico e profissional da tradução participam do seu desenvolvimento que se estrutura em três fases. Na primeira fase, foi preparado um documento com uma proposta inicial de descritores de nível, que inclui uma escala de três níveis com subníveis e cinco categorias descritivas (competência linguística; competência cultural, enciclopédica e temática; competência instrumental; competência de prestação de serviços de tradução e competência de resolução de problemas de tradução). Esta proposta será avaliada por especialistas do mundo acadêmico e profissional. O presente trabalho apresenta o projeto e a primeira proposta de nivelamento elaborada.

Palavras-chave: Níveis de Competência; Quadro Europeu; Escalas de Descritores; Competência Tradutória; Aquisição da Competência Tradutória

\title{
ESTABLISHING LEVELS OF COMPETENCE IN TRANSLATION: FIRST RESULTS OF THE NACT PROJECT
}

\begin{abstract}
This paper presents the research project the PACTE group is carrying out on "Establishing Competence Levels in the Acquisition of Translation Competence in Written Translation". The project aims to propose level descriptors as a first step towards developing a common European framework of reference for translation's academic and professional arenas. The project is a continuation of PACTE's previous experimental research on translation competence and its acquisition. Representatives of both academic and professional arenas participate in the project. It is organized into three stages, the first of which involved the production of a first level descriptor proposal, including a three-level scale with sub-levels and five descriptive categories (language competence; cultural, world knowledge, and thematic competence; instrumental competence; translation service provision competence; and translation problem solving competence). This proposal produced is to be evaluated by experts from the academic and professional arenas. This paper sets out the project, as well as the first level descriptor proposal.
\end{abstract}

Keywords: Competence Levels; European Framework; Descriptor Scales; Translation Competence; Translation Competence Acquisition 


\section{Introdução}

O objetivo deste artigo é apresentar o projeto de pesquisa que o grupo PACTE está realizando sobre o Nivelamento de Competências na Aquisição da Competência Tradutória (tradução escrita) (NACT), financiado pelo Ministério da Economia e Competitividade espanhol (FFI2013-42522-P).

Diferentemente de outras disciplinas, na tradução não há uma base comum para descrever os níveis de competência, como é o caso do ensino de línguas (por exemplo, o Quadro Europeu Comum de Referência para as Línguas, QECR). Tal descrição forneceria uma estrutura comum de grande interesse para os setores de tradução tanto educacional quanto profissional.

Cabe ressaltar, em primeiro lugar, que a formação de tradutores é uma formação específica que prepara para a profissão de tradutor, de modo que seu objetivo é desenvolver a competência tradutória, a qual é qualitativamente diferente da competência bilíngue. Nesse sentido, é necessário estabelecer a diferença entre os níveis de competência linguística (por exemplo, o QECR) e os níveis de competência tradutória.

Deve-se considerar também que existem diferentes níveis de formação de tradutores na Universidade (graduação, especialização, mestrado) e fora da Universidade. Além disso, há uma grande disparidade de critérios em termos dos níveis de formação necessários, de forma que, apesar de terem o mesmo título (graduação, mestrado), os níveis de formação alcançados podem diferir bastante, dependendo dos centros educacionais e/ou dos países. Em alguns países, inclusive, não há sequer uma formação específica em tradução, e esta se estabelece no âmbito de outras formações (em idiomas, filologia etc.), o que faz com que o nível de formação adquirido seja díspar. Devemos acrescentar a tudo isso os requisitos de unificação acadêmica introduzidos pelo Espaço Europeu de Ensino Superior, os quais condicionam uma homogeneização e uma transparência dos níveis de formação alcançados em cada centro educacional. 
No mercado de trabalho, por sua vez, existem diferentes níveis de desempenho e especialização (tradutores profissionais e não profissionais de diferentes tipos e níveis). Além disso, a globalização do mercado de tradução exige uma maior especificidade do nível de desempenho que cada tradutor pode garantir, bem como dos requisitos que devem ser atendidos em cada caso.

A crescente mobilidade acadêmica e profissional no campo da tradução é outro fator adicionado à exigência de concretude e transparência dos possíveis níveis de desempenho.

Nesse sentido, a descrição dos níveis de desempenho na tradução forneceria uma estrutura comum nos setores profissional e educacional da área, o que facilitaria a comparação entre diferentes sistemas de classificação. Ademais, essa descrição serviria de orientação para: desenvolver programas de tradução; projetar avaliações (elaboração de provas, desenho de avaliação formativa e diagnóstica); elaborar manuais e materiais de ensino; determinar certificações; reconhecer e validar títulos; estabelecer perfis educacionais e profissionais; estabelecer diretrizes profissionais de controle de qualidade.

O objetivo do Projeto NACT é justamente determinar níveis de desempenho na tradução, que forneçam uma base comum de referência europeia nos setores profissional e educacional e que sirvam para regular a progressão. Essa investigação é baseada nos resultados obtidos em pesquisas experimentais anteriores desenvolvidas pelo PACTE sobre competência tradutória (CT) e aquisição de competência tradutória (ACT) e conta com a participação de pesquisadores dos mundos acadêmico e profissional da tradução.

Como se trata do primeiro passo para estabelecer níveis de desempenho em tradução e como o Projeto tem duração de apenas quatro anos, os vários perfis profissionais da especialização (jurídica, econômica e financeira, técnica, científica, literária etc.) não são descritos e suas descrições são deixadas para um futuro Projeto de Pesquisa. A descrição refere-se aos primeiros níveis de iniciação à tradução e ao perfil do tradutor geral.

Este artigo descreve o Projeto e apresenta a primeira proposta de descritores elaborada, a qual será submetida ao julgamento de espe- 
cialistas do mundo acadêmico e profissional ${ }^{2}$. No final do artigo, cinco apêndices são incluídos com os descritores de nível elaborados.

\section{Descrição do Projeto NACT}

\subsection{Objetivos}

O objetivo da pesquisa é estabelecer uma proposta de descritores de nível para a tradução escrita que seja um primeiro passo no desenvolvimento de uma base europeia comum de referência nos setores educacional e profissional da tradução, comparável ao QECR no caso das línguas. Nesse sentido, são definidos os seguintes objetivos:

1. Descrever as competências específicas envolvidas na aquisição da competência tradutória.

2. Descrever os níveis de desempenho em tradução.

Como já indicado, os perfis de especialização profissional do tradutor não são descritos; são descritos apenas os níveis de iniciação e aqueles próprios ao tradutor geral.

O Projeto não procura descrever resultados de aprendizagem ou propor critérios para cada ciclo educacional ou campo profissional, mas sugerir níveis de desempenho que cada contexto educacional ou profissional poderia utilizar de acordo com suas necessidades. Além disso, a descrição é feita independentemente da combinação linguística e da direcionalidade (tradução direta, tradução reversa). Também é independente da carga horária, uma vez que se trata de um aspecto curricular.

${ }^{2}$ Cf. PACTE (e) para uma descrição mais detalhada do marco conceitual e da metodologia, bem como para uma apresentação dos três documentos anexados à proposta com exemplos de: gêneros textuais; conhecimentos culturais e enciclopédicos; e ferramentas tecnológicas.

Cad. Trad., Florianópolis, v. 40, n 2, p. 429-464, mai-ago, 2020. 


\subsection{Marco conceitual}

A pesquisa é enquadrada em um marco conceitual duplo: (1) pesquisas sobre competência tradutória e aquisição de competência tradutória; (2) investigações sobre as escalas dos descritores.

Em primeiro lugar, foram consideradas as propostas para a descrição das CTs e para sua aquisição, as quais foram elaboradas nos mundos acadêmico e profissional ${ }^{3}$. Em particular, são considerados os resultados obtidos em investigações experimentais anteriores realizadas pelo PACTE sobre CT (Hurtado Albir, 2017(b)) e sobre ACT (PACTE, (c), (d)); essas investigações serviram para validar os modelos de CT e de ACT do PACTE (PACTE, (a), (b), (c)). O PACTE considera que a CT é o sistema subjacente de conhecimentos, habilidades e atitudes necessárias para traduzir. Segundo os pesquisadores do grupo, a CT é composta por cinco subcompetências (bilíngue, extralinguística, instrumental, estratégica e conhecimentos de tradução) e por componentes psicofisiológicos. Também foi considerada a descrição de competências elaborada em 2009 pelo grupo de especialistas do EMT (European Master's in Translation), a qual distingue seis competências (linguística, intercultural, temática, tecnológica, de documentação e de prestação de serviços de tradução).

Além disso, foram consultadas propostas de descritores de competências feitas a partir do campo profissional da tradução: a descrição das competências do tradutor profissional da National Occupational Standards do Reino Unido (Skills CFA); a descrição dos níveis para a certificação de tradutores elaborada pela NAATI (National Accreditation Autorithy for Translators and Interpreters) da Austrália, ainda em revisão (Improvements to NAATI Testing, INT) Também foi consultada a descrição do programa de Certificação da ATA (American Translators Association) e o código de conduta profissional do ITI (Institute of Translation and Interpreting).

\footnotetext{
${ }^{3}$ Para uma revisão dos modelos de CT, consulte Hurtado Albir ((a): 382-400, (c): 18-33) e Koby; Melby (2013). Para uma revisão dos modelos de ACT, consulte Hurtado ((a): 401-408).
}

Cad. Trad., Florianópolis, v. 40, n 2, p. 429-464, mai-ago, 2020. 
Para a descrição dos aspectos culturais, consultamos: a estrutura curricular da competência intercultural do PICT (Promoting Intercultural Competence in Translators); o modelo de competência intercultural de Yarosh ((a), (b)); as dimensões da competência intercultural propostas pelo projeto INCA (Intercultural Competence Assessment); as competências multilíngues e multiculturais da versão expandida do QECR (CEFR Illustrative Descriptors Extended Version, 2016, versão piloto).

Em um segundo momento, consideramos as pesquisas sobre as escalas de descritores. Tais investigações incluem categorias descritivas (horizontais) e descritores de níveis (verticais). Em particular, foi considerada a descrição de escalas de nível para idiomas, desenvolvida para o QECR (Instituto Cervantes; Conselho da Europa (a)). A descrição de "Translating" também foi consultada na seção "Mediation" da versão piloto expandida do mesmo conselho (Conselho de Europa, (b)).

\subsection{Metodologia}

Na pesquisa são utilizados métodos essencialmente qualitativos e também quantitativos descritivos. O Projeto teve duração de quatro anos (2015-2018) e a pesquisa está estruturada em três fases:

- A primeira fase foi concluída em maio de 2017. Seu objetivo foi elaborar uma proposta inicial de descritores de níveis. Para esse fim, foram compilados e analisados: a) documentação curricular (especialização e mestrado) de 18 centros europeus de formação de tradutores; b) propostas de competências exigidas de tradutores nos âmbitos acadêmico e profissional.

- Na segunda fase, iniciada em junho de 2017, pretende-se avaliar a proposta de descritores por meio do julgamento de especialistas do mundo acadêmico e do mundo profissional da tradução, que preencherão um questionário avaliativo da proposta. 
- O objetivo da terceira fase (2018) é analisar os dados obtidos por meio de julgamento de especialistas e formular uma proposta revisada de descritores de nível.

$\mathrm{Na}$ investigação participam:

1. Representantes do mundo acadêmico da tradução (instituições e docentes). Na primeira fase do projeto, contamos com a colaboração de 23 centros europeus de formação de tradutores ${ }^{4}$ de 15 países (Alemanha, Bélgica, Eslovênia, Espanha, Finlândia, França, Grécia, Holanda, Itália, Polônia, Portugal, Reino Unido, Romênia, Suécia e Suíça). Sua função é fornecer material curricular de seus centros e atuar como um painel de especialistas para avaliar a proposta de descritores de nível.

2. Representantes do mundo profissional da tradução. Para a avaliação da proposta dos descritores. Haverá representantes do mundo profissional da tradução na Europa: associações profissionais e tradutores gerais de vários países.

Além disso, houve o aconselhamento de dois especialistas fora do mundo da tradução: um especialista em nivelamento e um especialista em gerenciamento de projetos educacionais. Há também a colaboração da Direção Geral de Tradução da Comissão Europeia (departamento de língua espanhola).

\footnotetext{
4 Os centros pertencem às seguintes universidades (em ordem alfabética): Ióvı

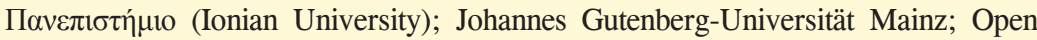
University; Stockholms Universitet; Universitatea Alexandru Ioan Cuza; Universiteit Antwerpen; Universitat Autònoma de Barcelona; Università di Bologna; University of Eastern Finland; Université de Genève; Universiteit Gent; Universidad de Granada; Universität Hildesheim; Universitat Jaume I; Univerza v Ljubljani; Universidade Nova de Lisboa; Université Paris III; Università del Salento; Università degli Studi di Trieste; University of Westminster; Uniwersytet Wrocławski; Zürcher Hochschule für Angewandte Wissenschaften; Zuyd Hogeschool.
} 


\section{Primeira proposta de descritores de níveis}

Como resultado da primeira fase da pesquisa, em março de 2017, foi elaborado um documento bilíngue (espanhol e inglês) com uma proposta inicial de descritores de nível: Nivelamento de Competências em Tradução. Proposta $1^{5}$. Para sua confecção, partiu-se da análise da documentação curricular de 18 centros europeus de formação de tradutores e das proposições de CT desenvolvidas a partir dos âmbitos acadêmico e profissional (cf. 2.2). Os resultados dos experimentos do PACTE foram especialmente úteis para a definição dos descritores relacionados às capacidades estratégicas para resolver problemas de tradução, bem como aos conhecimentos extralinguísticos e à competência instrumental. Para a definição de aspectos relacionados às competências profissionais, baseamo-nos fundamentalmente nas propostas do EMT, NAATI e do National Occupational Standards do Reino Unido.

$\mathrm{O}$ documento elaborado foi apresentado e discutido em uma reunião com representantes dos centros e instituições colaboradores no Projeto, realizada na Faculdade de Tradução e Interpretação da Universidade Autônoma de Barcelona, em 16 de março de 2017. Posteriormente, ocorreu um fórum virtual entre os participantes da reunião para continuar o debate. Após os dois encontros, algumas modificações foram introduzidas na proposta. Esta Proposta 1 revisada é a que será submetida ao parecer de especialistas e apresentada nos apêndices.

\subsection{Níveis de tradução propostos}

Na proposta elaborada, buscou-se, por um lado, estabelecer uma série de níveis que mostram diferenças em uma escala pro-

\footnotetext{
${ }^{5}$ Para a preparação deste documento, recebemos o conselho de Esther Adot, da Agència per a la Qualitat del Sistema Universitari (AQU) da Catalunha; Álvaro García Santa Cecília, do Instituto Cervantes; Dorothy Kelly, da Universidade de Granada; Catherine Way, da Universidade de Granada.
}

Cad. Trad., Florianópolis, v. 40, $\mathrm{n}^{0}$ 2, p. 429-464, mai-ago, 2020. 
gressiva e, por outro lado, não exceder os níveis que um tradutor profissional é capaz de distinguir e exercer. Uma escala de três níveis foi utilizada, com subníveis, seguindo o modelo do QECR. Os níveis propostos são:

- Nivel de tradução $C$. Competências correspondentes a cada perfil profissional (consolidação das áreas de especialização do tradutor): tradutor profissional especialista. Consideramos que os campos profissionais que devem ser descritos são: tradução jurídica; tradução econômica e financeira; tradução técnica; tradução científica; tradução literária; tradução audiovisual (dublagem, legendagem, sobreposição de vozes); acessibilidade (audiodescrição, legendagem para surdos); localização (páginas da web, softwares, videogames) ${ }^{6}$. Esse nível é um caso especial, pois deveria incluir a descrição de cada um dos campos profissionais de especialização, o que requer a obtenção de informações adicionais de profissionais de cada campo e de docentes especializados em sua formação. No momento, só foi descrito de uma maneira geral e a especificidade de cada área não foi determinada, exceto no que se refere à descrição dos gêneros textuais (cf. abaixo). Os gêneros textuais foram descritos para haver uma referência de até onde o nível $\mathrm{B}$ deve ir, para criar diretrizes e propor pontos de corte de mudança dos níveis $\mathrm{B}$ para $\mathrm{C}$ e a fim de não exceder os níveis que um tradutor profissional é capaz de distinguir e exercer. A descrição do nível C será realizada em nossa próxima pesquisa e, consequentemente, ainda está por ser desenvolvida.

- Nivel de tradução B. Habilidades básicas de tradução especializada (introdução às áreas de especialização do tradutor): tradutor geral profissional.

\footnotetext{
${ }^{6}$ A tradução juramentada não está incluída, pois é um credenciamento oficial de certos países que exige o domínio de qualquer área de especialização (jurídica, administrativa, econômica, científica, técnica etc.).
} 
- Nivel de tradução A. Habilidades básicas de tradução (iniciação da tradução): tradutor pré-profissional.

Os níveis A e B foram divididos em dois subníveis: A1 e A2; B1 e B2. O nível C não foi subdividido e, como já foi dito, consiste apenas em uma descrição geral.

Os níveis são cumulativos, ou seja, cada nível pressupõe o domínio do nível inferior. Por esse motivo, os descritores do nível anterior não são repetidos na descrição.

Para cada nível, foram propostos os gêneros textuais que se deveria ser capaz de traduzir. A progressão da dificuldade que foi estabelecida vai de gêneros não especializados a gêneros especializados em vários campos. No entanto, o gênero textual não é a única categoria na evolução da dificuldade de tradução, pois este deve ser combinado com os descritores da competência de resolução de problemas de tradução, o que complementa o grau de dificuldade em cada nível (ver seção 3.2).

- Nivel de Tradução C (tradutor especialista profissional). Textos especializados de, pelo menos, um campo de domínio profissional (jurídico, econômico e financeiro, científico, técnico, literário, audiovisual, acessibilidade, localização). Note-se que em algumas áreas de especialização (audiovisual, acessibilidade, localização) os textos traduzidos nem sempre são especializados; Nestes casos, a especialização é dada pelo tipo de suporte e pelas características da modalidade.

- Nível de Tradução B2 (tradutor geral profissional). Textos semiespecializados (destinados a um público de não especialistas) de pelo menos um campo profissional (jurídico-administrativo, econômico e financeiro, técnico, científico, editorial de cunho não literário).

- Nível de Tradução B1 (tradutor geral profissional). Textos não especializados de pelo menos um campo profissional (jurídico-administrativo, econômico e financeiro, técnico, científico, editorial de cunho não literário). 
- Nível de Tradução A2 (tradutor pré-profissional). Textos não especializados que apresentam problemas de registro (tom, estilo) de vários tipos textuais (narrativo, descritivo, expositivo, argumentativo, instrutivo).

- Nivel de Tradução A1 (tradutor pré-profissional). Textos não especializados na linguagem padrão de vários tipos de texto (narrativo, descritivo, expositivo, argumentativo, instrutivo).

Preparamos um documento (que se encontra anexado) o qual inclui exemplos de gêneros textuais que podem ser traduzidos em cada nível. A progressão de gêneros textuais que foi estabelecida é marcada por uma dificuldade crescente. Cada nível contém exemplos de gêneros que o indivíduo deve ser capaz de traduzir. No nível $\mathrm{A}$, os gêneros foram agrupados por tipos de texto: narrativo, descritivo, expositivo, argumentativo, instrutivo. No nível B, por áreas profissionais próprias do tradutor geral: jurídico-administrativa; econômica e financeira; técnica científica; editorial de cunho não literário. No nível $\mathrm{C}$, por âmbito de especialização profissional: jurídica; econômica e financeira, científica, técnica, literária, audiovisual, acessibilidade, localização.

\subsection{Categorias descritivas propostas}

As categorias descritivas usadas são competências. Foram propostas as seguintes competências, que são as mais recorrentes nas proposições realizadas tanto no mundo acadêmico quanto no profissional da tradução (cf. 2.2): competência linguística; competência cultural, enciclopédica e temática; competência instrumental; competência de prestação de serviços de tradução; competência de resolução de problemas. Essas categorias estão inter-relacionadas, já que interagem e equilibram-se na configuração de cada nível. Nesse sentido, pode não haver mudança de um nível para outro em algum descritor de uma categoria, mas sim nas outras categorias. Além disso, as cinco categorias interagem e se compensam para garantir 
a qualidade da tradução de cada nível (por exemplo, a compensação entre competência cultural, enciclopédica, temática e instrumental).

Apresentamos abaixo as características fundamentais de cada categoria. Nos anexos do artigo, pode-se consultar a escala de descritores proposta para cada categoria.

\section{Competência Linguística}

É descrita em termos de compreensão leitora na língua fonte e de produção escrita na língua meta, em relação aos gêneros que podem ser traduzidos em cada nível e seguindo os níveis do QECR (ver Apêndice 1). No Nível de Tradução A1, é proposto um mínimo de nível B2 em compreensão de leitura e de nível $\mathrm{C} 1$ em produção escrita do $\mathrm{QECR}^{7}$; no Nível de Tradução $C$, sugere-se um nível $\mathrm{C} 2$ do QECR em ambos os casos. O estabelecimento desses níveis mínimos de competência linguística é um elemento essencial para a homogeneização dos níveis de CT.

\section{Competência Cultural, Enciclopédica e Temática}

Refere-se à mobilização de conhecimentos sobre a cultura estrangeira e sobre a própria cultura, bem como ao conhecimento enciclopédico (universal) e temático de áreas específicas para resolver problemas de tradução ( $c f$. Apêndice 2). A progressão da dificuldade dos referentes culturais foi estabelecida em relação ao seu nível de explicitação no texto e ao nível de complexidade do conhecimento necessário (básico ou avançado) para traduzi-lo. A resolução dos aspectos temáticos começa no nível $\mathrm{B} 1$ e avança na mobilização de conhecimentos temáticos básicos (nível B) até chegar aos especializados (nível C).

Um documento encontra-se anexado ao final de nosso trabalho no qual se incluem exemplos de conhecimento cultural e enciclo-

\footnotetext{
${ }^{7}$ De acordo com os dados do material curricular dos 18 centros de formação de tradutores analisados (cf. 2.3), o nível mínimo exigido principalmente em uma língua estrangeira é B2 do QECR.
}

Cad. Trad., Florianópolis, v. 40, nº 2, p. 429-464, mai-ago, 2020. 
pédico para os níveis A e B. Nenhuma diferença foi estabelecida entre A1 e A2 e B1 e B2, considerando que o tipo de conhecimento extralinguístico necessário para traduzir os gêneros daqueles níveis não representa mudanças substanciais no conhecimento; Além disso, seria difícil garantir mudanças importantes nesse conhecimento do ponto de vista do aprendizado da tradução.

\section{Competência Instrumental}

Está relacionada ao uso de recursos de documentação (tipo de recursos e consultas) e de ferramentas tecnológicas ( $c f$. Apêndice 3). Nesse caso, a progressão na descrição dos níveis é estabelecida em termos de: uso de recursos de documentação com base nos gêneros textuais de cada nível; tipo de consultas (básicas ou complexas); ferramentas tecnológicas (básicas ou avançadas) e funções que podem ser usadas nessas ferramentas (básicas ou avançadas).

Foi preparado um documento em anexo que inclui exemplos de ferramentas e funcionalidades tecnológicas para os níveis A e B, estabelecendo uma progressão em seu uso. Para os níveis A1 e A2, é proposto o domínio de processadores de texto, mecanismos gerais de pesquisa na Internet e gerenciadores de e-mail; para o nível B1, o domínio das ferramentas de conversão de documentos; para o nível B2, o domínio de mecanismos de pesquisa especializados, ferramentas de tradução assistida por computador, alinhamento de texto, linguística de corpus aplicada à tradução e ferramentas de gerenciamento de contabilidade e orçamento.

\section{Competência de Prestação de Serviços de Tradução}

Inclui a gestão de assuntos relacionados ao funcionamento do mercado de trabalho e ao exercício da profissão ( $c f$. Apêndice 4). Varia de acordo com o campo profissional e com o tipo de empregabilidade do tradutor (tradutor em órgãos públicos, empresas de tradução, autônomos etc.), portanto, os descritores pertinentes devem ser considerados de acordo com cada caso. 
Esta competência começa a se desenvolver especialmente no nível B1. No nível A, apenas algumas questões básicas relacionadas à tarefa de tradução estão incluídas.

\section{Competência de Resolução de Problemas de Tradução}

Esta categoria descreve os tipos de problemas de tradução que podem ser resolvidos em cada nível ( $c f$. Apêndice 5). É a categoria central que serve de orientação para o restante das categorias, pois define as competências necessárias em cada nível. Esta categoria descritiva está diretamente relacionada aos gêneros textuais que se deveria ser capaz de traduzir em cada nível.

Foi proposta uma progressão da dificuldade dos problemas que devem ser resolvidos em cada nível. As interferências linguísticas devem ser resolvidas nos níveis A (em A1, problemas básicos; em A2, também aqueles derivados da variação linguística). A intencionalidade é introduzida em A2 e questões temáticas e derivadas de tarefas de tradução profissional a partir de B1.

\subsection{Características da Escala de Descritores Proposta}

É importante ter em mente que os descritores de competências devem sempre ter um caráter prático. Todos os descritores são assim formulados em termos de capacidade de atuação (é capaz de) e envolvem a mobilização e a aplicação de conhecimentos. Por esse motivo, descritores de conhecimento declarativo da tradução não foram incluídos. O conhecimento declarativo do tradutor é útil apenas se puder ser aplicado durante a tradução, para resolver problemas de tradução. Consequentemente, a mobilização e aplicação do conhecimento declarativo estão incluídas em alguns descritores da competência denominada Resolução de Problemas de Tradução (nos níveis A1 e A2). A mobilização de conhecimentos relacionados à tarefa de traduzir está incluída na competência nomeada Prestação de Serviços de Tradução (nos níveis A1 e A2). 
Também queremos destacar que, por se tratar de uma proposta que visa avançar na elaboração de um Quadro de Referência, buscou-se uma formulação dos descritores que fosse clara, simples e fácil de observar, a fim de favorecer seu uso em diversos contextos acadêmicos e profissionais. Por esse motivo, não foram utilizados mais indicadores de ordem cognitiva (por exemplo, identificar, planejar, avaliar, justificar, usar estratégias), muito úteis do ponto de vista pedagógico, mas mais difíceis de serem observados do ponto de vista profissional. Dessa forma, por exemplo, nos descritores de competência instrumental, não foram introduzidos indicadores do tipo "planejamento de pesquisas", "avaliação do resultado das pesquisas"; ou, nas competências cultural, enciclopédica e temática, não foram incluídos indicadores de atitudes interculturais (tais como mostrar uma atitude aberta em relação a outras realidades culturais, estar ciente de estereótipos e preconceitos sobre a cultura estrangeira na própria cultura, ter empatia com a cultura estrangeira); ou mesmo na competência de resolução de problemas de tradução, nenhum descritor foi incluído no uso de estratégias cognitivas para a solução de problemas. Cada desenho curricular deve incorporá-los de acordo com as necessidades do contexto.

Nenhuma classificação ou gradação da qualidade da tradução foi especificada de acordo com os níveis. O critério de qualidade está diretamente relacionado ao conceito de competência. Não se pode ser competente em um nível se o que é produzido não for de qualidade. Por esse motivo, os graus de qualidade não foram estabelecidos em cada nível, muito embora essa descrição seja necessária no campo acadêmico, exigindo uma definição específica de acordo com os contextos pedagógicos e com suas necessidades.

A proposição apresentada não se concentra na descrição dos resultados da aprendizagem. Também não incorpora a atribuição e descrição de tarefas pedagógicas de cada nível, como a identificação de problemas, a tradução de ideias-chave, a identificação de erros, a tradução sintética, a correção de textos etc. A inclusão de resultados de aprendizagem e tarefas pedagógicas para cada um dos níveis 
propostos seria particularmente benéfica para o campo acadêmico, mas requer uma outra investigação.

No caso do nível $\mathrm{C}$, tarefas profissionais adicionais também deveriam ser incorporadas à tradução de textos específicos para cada área de especialização, como o gerenciamento de projetos, a criação de bancos de dados terminológicos, a adaptação de textos, a redação técnica, a revisão, a pós-edição etc. No nível B2, foram incluídas tarefas profissionais, como a revisão e pós-edição dos textos apropriados a um tradutor geral, uma vez que cabe a ele realizá-las atualmente.

\subsection{Descrição de uma Escala Global}

Também foi desenvolvida uma escala global (cf. Tabela 1), que identifica os recursos essenciais a cada nível.

Em cada nível, o primeiro descritor resume o que e como devese ser capaz de traduzir. O nível mínimo do QECR exigido para compreensão da leitura na língua fonte e para a produção escrita na língua meta também é especificado. Além disso, foram incluídos descritores da competência de resolução de problemas de tradução, por ser esta a principal: trata-se do $2^{\circ}$ ou $3^{\circ}$ descritor, de acordo com o nível.

Um descritor para as competências instrumentais e de prestação de serviços de tradução também está incluso em cada nível. Nenhum descritor de competência cultural, enciclopédica e temática foi apresentado porque seu uso já foi mostrado nos descritores relacionados à resolução de problemas.

\section{Tabela 1: Escala global}

Nível de Tradução C

1. É capaz de traduzir textos especializados em pelo menos um campo profissional de especialização (jurídico, econômico e financeiro, técnico, científico, literário, audiovisual, acessibilidade, localização), para o qual é exigido um nível mínimo de compreensão leitora C2 na língua fonte e de produção escrita C2 na língua meta de acordo com o QECR (podem existir características especiais dependendo do campo de especialização). 
2. É capaz de resolver problemas específicos do campo profissional de especialização.

3. É capaz de identificar e usar recursos confiáveis de documentação e usar ferramentas tecnológicas para resolver esses problemas de tradução, além de adaptar-se a novos recursos de documentação e ferramentas tecnológicas.

4. É capaz de gerenciar questões relacionadas ao funcionamento do mercado de trabalho e ao exercício da profissão do campo profissional de especialização.

\section{[A ser desenvolvido]}

\section{Nível de Tradução B2}

1. É capaz de traduzir textos semiespecializados destinados a um público de não especialistas) de pelo menos um campo profissional (jurídico-administrativo, econômico e financeiro, técnico, científico, editorial de cunho não literário) em situações de tradução profissional para destinatários não especialistas sem cometer erros de significado, com correção linguística e apropriados à demanda, para os quais é necessário um nível mínimo $\mathrm{C} 1$ de compreensão de leitura na língua fonte e $\mathrm{C} 2$ de produção escrita na língua meta de acordo com o QECR.

2. É capaz de executar diferentes tipos de tradução de acordo com a demanda.

3. É capaz de resolver problemas de interferência linguística, temas básicos, discrepância cultural e enciclopédicos de natureza explícita e implícita, além de intencionalidade.

4. É capaz de identificar e usar recursos confiáveis de documentação e usar ferramentas tecnológicas para resolver problemas de tradução, além de se adaptar a novos recursos de documentação e ferramentas tecnológicas.

5. É capaz de gerenciar questões relacionadas ao funcionamento do mercado de trabalho e ao exercício da profissão.

\section{Nível de Tradução B1}

1. É capaz de traduzir textos especializados de pelo menos um âmbito profissional (jurídico-administrativo; econômico e financeiro; técnico; científico; editorial de cunho não literário) em situações de tradução profissional para destinatários não especialistas sem cometer erros de significado, com correção linguística e adequada à demanda, para o que se requer um nível mínimo de compreensão de leitura $\mathrm{C} 1$ na língua fonte e de produção escrita $\mathrm{C} 2$ na língua meta de acordo com o QECR.

2. É capaz de resolver problemas de interferência linguística, temas básicos, discrepância cultural e enciclopédicos de natureza explícita e implícita, além de intencionalidade.

3. É capaz de identificar e usar recursos confiáveis de documentação e usar ferramentas tecnológicas para resolver esses problemas de tradução.

4. É capaz de distinguir questões básicas relacionadas ao mercado de trabalho da tradução. 


\section{Nível de Tradução A2}

1. É capaz de traduzir textos não especializados com problemas de registro em contextos não profissionais sem cometer erros de significado, com correção linguística e adequados à tarefa, para os quais é necessário um nível mínimo de compreensão de leitura B2 na língua fonte e de produção escrita $\mathrm{C} 1$ na língua meta de acordo com o QECR.

2. É capaz de resolver problemas de interferência linguística, derivados de variação linguística, discrepância cultural e enciclopédicos de natureza explícita, além de intencionalidade.

3. É capaz de identificar e usar recursos confiáveis de documentação e usar ferramentas tecnológicas para resolver esses problemas de tradução.

\section{Nível de Tradução A1}

1. É capaz de traduzir textos não especializados com problemas de registro em contextos não profissionais sem cometer erros de sentido, com correção linguística e adequados à tarefa, para os quais é necessário um nível mínimo de compreensão de leitura B2 na língua fonte e de produção escrita $\mathrm{C} 1$ na língua meta de acordo com o QECR.

2. É capaz de resolver problemas básicos de interferência linguística e problemas culturais e enciclopédicos básicos de natureza explícita.

3. É capaz de identificar e usar recursos confiáveis de documentação e usar ferramentas tecnológicas para resolver esses problemas de tradução.

\section{Considerações finais}

Como conclusão, queremos sublinhar as principais características dos descritores propostos.

1. Pretende servir ao campo acadêmico e profissional.

2. É independente da combinação linguística, da direcionalidade (tradução direta/reversa), dos ciclos educacionais e dos contextos profissionais, de modo que cada contexto educacional ou profissional possa usá-lo de acordo com suas necessidades.

3. Não inclui a descrição dos vários campos profissionais de especialização do nível $\mathrm{C}$, que só foram descritos de maneira geral. Esse é um nível especial, pois cada área profissional deve ser descrita e requer uma investigação posterior. 
4. A progressão estabelecida em cada categoria descritiva possui caráter cumulativo, ou seja, cada nível assume o domínio do inferior.

5. Todas as categorias descritivas estão inter-relacionadas, interagindo e compensando-se entre si.

6. Buscou-se formular os descritores de nível de uma maneira que seja clara, simples e fácil de observar, para promover seu uso em vários contextos acadêmicos e profissionais e para que seja claramente inteligível pelos possíveis usuários das escalas (estudantes e professores de tradução, tradutores e empregadores).

7. Por serem descritores de competências, descrevem capacidades de atuação (é capaz de) e não conhecimentos declarativos.

8. Nenhum grau de qualidade da tradução é especificado de acordo com os níveis, assim cada contexto educacional ou profissional terá que o definir de acordo com suas necessidades.

9. Não inclui uma descrição dos resultados da aprendizagem ou uma atribuição e descrição de tarefas pedagógicas específicas para cada nível.

Na segunda fase da investigação, a proposta dos descritores será avaliada por meio do julgamento de especialistas dos mundos acadêmico e profissional para: avaliar a adequação dos níveis e categorias elaborados bem como suas denominações; corrigir os descritores e emitir juízo de valor sobre eles; avaliar a progressão proposta etc.

Nosso projeto visa ser apenas um primeiro passo no desenvolvimento de um Quadro Europeu de Referência para os níveis de tradução. Uma vez terminado, estará faltando:

1. Validar a proposta de descritores resultante. Para isso, a precisão da escala desenvolvida e a adequação dos descritores devem ser testadas com uma amostra ampla e representativa de alunos, professores e profissionais de tradução. 
2. Descrever e validar os diferentes campos profissionais do nível C.

3. Projetar e validar instrumentos de avaliação para cada nível.

\section{Referências}

Conselho da Europa (a). Quadro Europeu Comum de Referência para as Línguas (QECRL). Estrasburgo: Divisão de Política de Idiomas, 2001.

Conselho da Europa (b). Descritores Ilustrativos do QECR. Versão Estendida 2016 [versão piloto]. Estrasburgo: Divisão de Política de Idiomas, 2016.

Emt. Competências para tradutores profissionais, especialistas em comunicação multilíngue e multimídia, 2009. Disponível em: http://ec.europa.eu/dgs/ translation/programmes/emt/key_documents/emt_competences_translators en.pdf. Acesso em: julho 2017.

Hurtado Albir, Amparo (a). Traducción y Traductología. Introducción a la Traductología. 5. ed., Madrid: Cátedra, 2011.

Hurtado Albir, Amparo (Ed.) (b). Researching Translation Competence by PACTE Group. Amsterdam: John Benjamins Publishing Company, 2017.

Hurtado Albir, Amparo (c). "Translation and Translation Competence". In: Amparo Hurtado Albir (Ed.). Investigating Translation Competence by PACTE Group. Amsterdam: John Benjamins Publishing Company, 2017, p. 3-35.

Inca. The INCA Project: Intercultural Competence Assessment, 2009. Disponível em: https://ec.europa.eu/migrant-integration/librarydoc/the-incaprojectintercultu ralcompetence-assessment. Acesso em: julho 2017. 
Instituto Cervantes. Marco común europeo de referencia para las lenguas. Madrid: MECD. Anaya, 2002.

Koby, Geoffrey S.; Melby, Alan K. "Certification and Job Task Analysis (JTA): Establishing Validity of Translator Certification Examinations". Translation \& Interpreting. v. 5, núm. 1, (2013): 174-201.

Naati. Improvements to NAAT Testing (INT), 2016. Disponível em: https://www. naati.com.au/projects/improvements-to-naati-testing-int. Acesso em: julho 2017.

Pacte (a). "Acquiring Translation Competence: Hypotheses and Methodological Problems in a Research Project”. In: Beeby, A.; Ensinger, D.; Presas, M. (Eds.). Investigating Translation. Amsterdam: John Benjamins, 2002, p. 99-106.

Pacte (b). "Building a Translation Competence Model". In: Alves, F. (Ed.). Triangulating Translation: Perspectives in Process Oriented Research. Amsterdam: John Benjamins, 2003, p. 43-66.

Pacte (c). "First Results of PACTE Group's Experimental Research on Translation Competence Acquisition: The Acquisition of Declarative Knowledge of Translation". MonTI: Monografias de Traducción e Interpretación. núm. esp. 1, (2014): 85-115.

Pacte (d). "Results of PACTE's Experimental Research on the Acquisition of Translation Competence: The Acquisition of Declarative and Procedural Knowledge in Translation. The Dynamic Translation Index". Translation Spaces. v. 4, núm. 1, (2015): 29-53.

Pacte (e). "Competence levels in translation: working towards a European framework". The Interpreter and Translator Trainer. v. 12, núm. 2, (2018): $111-131$.

Pacte (f). "Evolution of the Efficacy of the Translation Process in Translation Competence Acquisition". Meta. v. 64, núm, 1, 2019.

PICT. Intercultural Competence. Curriculum Framework, 2012. Disponível em: http://www.pictllp.eu/en/curriculum-framework/curriculum-frameworkdocument. Acesso em: julho 2017. 
Skills CFA. “Translation". UK's National Occupational Standards, 2007. Disponível em: www.skillscfa.org/standards-qualifications/languageintercultural. Acesso em: julho de 2017.

Yarosh, M (a). Translator Intercultural Competence: The Concept and Means to Measure the Competence Development. 2012. Tese de doutorado, Universidade de Deusto.

Yarosh, M (b). "Translator Intercultural Competence: A Model, Learning Objectives, and Level Indicators". In: Cui, Y.; Zhao, W. (Eds.). Handbook of Research on Teaching Methods in Language Translation and Interpretation. Hershey: IGI Global, (2015): 160-178.

Recebido em: 20/02/2020

Aceito em: 06/04/2020

Publicado em maio de 2020

Amparo Hurtado Albir. E-mail: amparo.hurtado@uab.es. ORCID: https://orcid. org/0000-0002-4362-7183

Anabel Galán-Manãs. E-mail: isabel.galan@uab.cat. ORCID: https://orcid. org/0000-0002-5498-9171

Anna Kuznik. E-mail: anna.kuznik@uwr.edu.pl. ORCID: https://orcid.org/00000002-3567-5118

Christian Olalla-Soler. E-mail: christian.olalla@uab.cat. ORCID: https://orcid. org/0000-0001-9251-476X

Patricia Rodríguez-Inés. E-mail: patricia.rodriguez@uab.cat. ORCID: https:// orcid.org/0000-0001-7160-3827

Lupe Romero. E-mail: lupe.romero@uab.cat. ORCID: https://orcid.org/00000001-5593-1097

Talita Serpa. E-mail: talitasrp82@gmail.com. ORCID: https://orcid.org/00000003-3324-9593 


\section{APÊNDICES}

\section{Apêndice 1: Competência Linguística}

\section{NÍVEL DE TRADUÇÃO C}

1. É capaz de compreender em língua fonte textos especializados de pelo menos um campo profissional de especialização da tradução (legal; econômico e financeiro; técnico; científico; literário; audiovisual; acessibilidade; localização), para o qual é necessário um nível compreensão mínima de leitura C2 do QECR (podem existir características especiais dependendo do campo de especialização).

2. É capaz de produzir em língua meta textos especializados em pelo menos um campo profissional de especialização da tradução (legal; econômico e financeiro; técnico; científico; literário; audiovisual; acessibilidade; localização), para o qual é exigido um nível mínimo de produção escrita C2 do QECR (podem existir características especiais dependendo do campo de especialização).

[A ser desenvolvido]

\section{NÍVEL DE TRADUÇÃO B2}

1. É capaz de compreender em língua fonte textos semiespecializados (direcionados a um público não especialista) de pelo menos um campo profissional da tradução (jurídico-administrativo; econômico-financeiro; técnico; científico; editorial de cunho não literário), para o qual é necessário um nível mínimo de compreensão de leitura C1 do QECR.

2. É capaz de produzir em língua meta textos semiespecializados (dirigidos a um público não especialista) de pelo menos um campo profissional da tradução (jurídico-administrativo; econômico-financeiro; técnico; científico; publicação de cunho não literário), para o qual se requer um nível mínimo de produção escrita $\mathrm{C} 2$ do OECR.

\section{NÍVEL DE TRADUÇÃO B1}

1. É capaz de compreender em língua fonte textos semiespecializados (direcionados a um público não especialista) de pelo menos um campo profissional da tradução (jurídico-administrativo; econômico-financeiro; técnico; científico; não literário), para o qual é necessário um nível mínimo de compreensão de leitura C1 do QECR. 
2. É capaz de produzir em língua meta textos semiespecializados (dirigidos a um público não especialista) de pelo menos um campo profissional da tradução (jurídico-administrativo; econômico-financeiro; técnico; científico; editorial de cunho não literário), para o qual se requer um nível mínimo de produção escrita C2 do QECR.

\section{NÍVEL DE TRADUÇÃO A2}

1. É capaz de compreender em língua fonte textos não especializados com problemas de registro (tom e estilo) e vários tipos textuais, para os quais é necessário um nível mínimo de compreensão de leitura B2 do QECR.

2. É capaz de produzir em língua meta textos não especializados com problemas de registro (tom e estilo) e de vários tipos textuais, para os quais é exigido um nível mínimo de produção escrita $\mathrm{C} 1$ do QECR.

\section{NÍVEL DE TRADUÇÃO A1}

1. É capaz de compreender em língua fonte textos não especializados em linguagem padrão de vários tipos de texto, para os quais é necessário um nível mínimo de compreensão de leitura B2 do QECR.

2. É capaz de produzir em língua meta textos não especializados em linguagem padrão de vários tipos de texto na língua de destino, para os quais é exigido um nível mínimo de produção escrita $\mathrm{C} 1$ do QECR. 


\section{Apêndice 2: Competência Cultural, Enciclopédica e Temática}

\section{NÍVEL DE TRADUÇÃO C}

1. É capaz de mobilizar conhecimentos culturais, enciclopédicos e temáticos para resolver problemas extralinguísticos explícitos e implícitos de textos especializados específicos do campo profissional de especialização.

[A ser desenvolvido]

\section{NÍVEL DE TRADUÇÃO B2}

1. É capaz de mobilizar conhecimentos avançados das culturas envolvidas e identificar suas discrepâncias para resolver problemas de referências culturais explícitas e implícitas em textos não especializados de, pelo menos, um campo profissional.

2. É capaz de mobilizar conhecimentos enciclopédicos avançados para resolver problemas enciclopédicos explícitos e implícitos em textos semiespecializados (destinados a um público não especialista) de, pelo menos, um campo profissional.

3. É capaz de mobilizar conhecimentos temáticos básicos para resolver problemas de tradução de textos semiespecializados (destinados a um público não especializado) de, pelo menos, um campo profissional.

\section{NÍVEL DE TRADUÇÃO B1}

1. É capaz de mobilizar conhecimentos avançados das culturas envolvidas e identificar suas discrepâncias para resolver problemas de referências culturais explícitas e implícitas em textos não especializados de, pelo menos, um campo profissional.

2. É capaz de mobilizar conhecimentos enciclopédicos avançados para resolver problemas enciclopédicos explícitos e implícitos em textos não especializados de, pelo menos, um campo profissional,

3. É capaz de mobilizar conhecimentos temáticos básicos para resolver problemas de tradução de textos não especializados de, pelo menos, um campo profissional.

\section{NÍVEL DE TRADUÇÃO A2}

1. É capaz de mobilizar conhecimentos básicos das culturas envolvidas e identificar suas discrepâncias para resolver problemas de referências culturais explícitas em textos não especializados que apresentam problemas de registro. 
2. É capaz de mobilizar conhecimentos enciclopédicos básicos para resolver problemas enciclopédicos explícitos em textos não especializados que apresentam problemas de registro.

\section{NÍVEL DE TRADUÇÃO A1}

1. É capaz de mobilizar conhecimentos básicos das culturas envolvidas e identificar suas discrepâncias para resolver problemas de referências culturais explícitas em textos não especializados em linguagem padrão.

2. É capaz de mobilizar conhecimentos enciclopédicos básicos para resolver problemas enciclopédicos explícitos em textos não especializados em linguagem padrão. 


\section{Apêndice 3: Competência Instrumental (recursos de documentação e ferramentas tecnológica}

\section{NÍVEL DE TRADUÇÃO C}

1. É capaz de usar recursos confiáveis de documentação do âmbito de especialização (sempre que a combinação linguística e o contexto permitirem).

2. É capaz de realizar consultas complexas em tais recursos (por exemplo, usando operadores booleanos, restringindo buscas por critérios, usando métodos avançados de busca fornecidos pelos recursos etc.), combinando tipos de recursos e consultas.

3. É capaz de utilizar funcionalidades avançadas das ferramentas tecnológicas específicas do campo profissional de especialização (sempre que a combinação linguística e o contexto permitirem).

4. É capaz de se adaptar a novos recursos de documentação e ferramentas tecnológicas.

5. É capaz de adaptar ferramentas tecnológicas as suas necessidades (melhorar ferramentas, alimentar bases de dados etc.).

\section{[A ser desenvolvido]}

\section{NÍVEL DE TRADUÇÃO B2}

1. É capaz de identificar e usar recursos de documentação confiáveis para solucionar problemas de tradução de textos semiespecializados (destinados a um público não especialista) de pelo menos um campo profissional; p. ex: especializados, corpora gerais e especializados, fóruns e blogs profissionais e expertos, consultas a tradutores especializados e especialistas de outras áreas (sempre que a combinação linguística e o contexto permitirem).

2. É capaz de realizar consultas complexas em tais recursos (por exemplo, usando operadores booleanos, restringindo buscas por critérios, usando métodos avançados de busca fornecidos pelos recursos etc.), combinando tipos de recursos e consultas.

3. É capaz de utilizar funcionalidades básicas de ferramentas tecnológicas especializadas para resolver problemas de tradução de textos semiespecializados (destinados a um público não especialista) de pelo menos um campo profissional; p. ex. buscadores especializados, tradução assistida por computador, alinhamento de textos, linguística de corpus aplicada à tradução (sempre que a combinação linguística e o contexto permitirem).

4. É capaz de se adaptar a novos recursos de documentação e ferramentas tecnológicas. 


\section{NÍVEL DE TRADUÇÃO B1}

1. É capaz de identificar e utilizar recursos de documentação confiáveis para resolver problemas de tradução de textos não especializados de pelo menos um campo profissional; p. ex. dicionários históricos e etimológicos, de neologismos, de gírias e coloquialismos, consultas a tradutores especializados e especialistas de outras áreas (sempre que a combinação linguística e o contexto permitirem).

2. É capaz de realizar consultas complexas em tais recursos (por exemplo, usando operadores booleanos, restringindo buscas por critérios, usando métodos avançados de busca fornecidos pelos recursos etc.), combinando tipos de recursos e consultas.

3. É capaz de utilizar funcionalidades básicas de ferramentas tecnológicas avançadas para resolver problemas de tradução de textos não especializados de pelo menos um campo profissional; p. ex. de conversão de documentos (sempre que a combinação linguística e o contexto permitirem).

\section{NÍVEL DE TRADUÇÃO A2}

1. É capaz de identificar e utilizar recursos de documentação confiáveis para resolver problemas de tradução de textos não especializados que apresentam problemas de registro; p. ex. dicionários de sinônimos e antônimos, de colocações, de dificuldades, enciclopédias, textos paralelos, fóruns, blogs, listas de distribuição, consultas orais (sempre que a combinação linguística e o contexto permitirem).

2. É capaz de realizar consultas complexas em tais recursos (por exemplo, usando operadores booleanos, restringindo buscas por critérios, usando métodos avançados de busca fornecidos pelos recursos etc.), combinando tipos de recursos e consultas.

3. É capaz de utilizar funcionalidades avançadas de ferramentas tecnológicas básicas para resolver problemas de tradução de textos não especializados que apresentam problemas de registro; p. ex. processadores de texto, buscadores gerais na Internet (sempre que a combinação linguística e o contexto permitirem).

\section{NÍVEL DE TRADUÇÃO A1}

1. É capaz de identificar e utilizar recursos de documentação básica confiáveis para resolver problemas de tradução de textos não especializados em linguagem padrão; p. ex. dicionários bilíngues ou monolíngues, buscadores gerais, gramática, manuais de estilo, textos paralelos, consultas orais (sempre que a combinação linguística e o contexto permitirem). 
2. É capaz de realizar consultas básicas em tais recursos (por exemplo, palavra-chave em um buscador geral, definição em um dicionário monolíngue, equivalência em um dicionário bilíngue) com poucas combinações de recursos e consultas.

3. É capaz de utilizar funcionalidades básicas de ferramentas tecnológicas simples para resolver problemas de tradução de textos não especializados em linguagem padrão; p. ex. processadores de texto, buscadores gerais na Internet, gerentes de e-mail (sempre que a combinação linguística e o contexto permitirem). 


\section{Apêndice 4: Competência de Prestação de Serviços de Tradução}

\section{NÍVEL DE TRADUÇÃO C}

1. É capaz de gerir questões relacionadas ao funcionamento do mercado de trabalho e ao exercício da profissão no campo de especialização em uso.

[A ser desenvolvido]

\section{NÍVEL DE TRADUÇÃO B2}

1. É capaz de cumprir efetivamente os padrões de qualidade exigidos pelo mercado de trabalho em cada contexto para textos traduzidos por um tradutor geral em, pelo menos, um campo profissional.

2. É capaz de satisfazer os requisitos deontológicos da profissão (confidencialidade, imparcialidade, não aceitar demandas para as quais não seja capacitado etc.) quando realiza uma tarefa de tradução e interage com os agentes envolvidos na tarefa de traduzir.

3. É capaz de revisar e pós-editar a tradução dos textos de um tradutor geral, atendendo aos padrões de qualidade exigidos pelo mercado de trabalho em cada contexto.

4. É capaz de usar estratégias de marketing para atrair e manter clientes e obter pedidos profissionais. [Se o campo de empregabilidade assim exigir]

5. É capaz de negociar com os agentes envolvidos na tarefa de tradução (clientes, outros profissionais), para determinar os prazos de entrega, taxas, método de cobrança, condições de trabalho, tipo de contrato, direitos e responsabilidades, as especificações do pedido etc., e é capaz de satisfazer as condições acordadas. [Se o campo de empregabilidade assim exigir]

6. É capaz de trabalhar em coordenação com os agentes envolvidos na tarefa de tradução (clientes, gerentes de projeto, outros tradutores, revisores, etc.) e manter um fluxo de trabalho eficaz. [Se o campo de empregabilidade assim exigir]

7. É capaz de determinar a rentabilidade de uma atribuição de tradução com base no tempo de dedicação, na taxa estabelecida e no tempo de entrega acordado. [Se o campo de empregabilidade assim exigir]

8. É capaz de preparar orçamentos e faturas em várias situações de tradução de acordo com padrões estabelecidos. [Se o campo de empregabilidade assim exigir]

9. É capaz de gerir as obrigações fiscais básicas (por exemplo, registro de atividade profissional, pedido de registro de operadores intracomunitários, declarações fiscais trimestrais ou anuais resultantes da atividade profissional, declaração de retenções, declaração de operações com terceiros), contratos 
tradução e possíveis conflitos de não pagamento (por exemplo, avisos, requisitos formais, procedimento de monitoramento, procedimento judicial). [Se o campo de empregabilidade assim exigir]

10. É capaz de gerir as obrigações fiscais básicas (por exemplo, registro de atividade profissional, pedido de registro de operadores intracomunitários, declarações fiscais trimestrais ou anuais resultantes da atividade profissional, declaração de retenções, declaração de operações com terceiros), contratos tradução e possíveis conflitos de não pagamento (por exemplo, avisos, requisitos formais, procedimento de monitoramento, procedimento judicial). [Se o campo de empregabilidade assim exigir]

11. É capaz de gerenciar tarefas administrativas relacionadas ao fluxo de trabalho (por exemplo, registro e controle de dados do cliente, taxas aplicadas, pedidos feitos, status de pagamento). [Se o campo de empregabilidade assim exigir]

12. É capaz de gerenciar o ambiente de trabalho físico (por exemplo, localização do espaço de trabalho, condições de iluminação) e virtual (por exemplo, organização de tela, gerenciamento de pastas, manutenção de ferramentas de trabalho).

\section{NÍVEL DE TRADUÇÃO B1}

1. É capaz de distinguir textos que ele possa traduzir corretamente.

2. É capaz de distinguir as habilidades profissionais exigidas do tradutor.

3. É capaz de identificar os diferentes campos de empregabilidade do tradutor: tradutor em organizações públicas e privadas; tradutor autônomo; empresas de tradução; empresas de outros setores que necessitam serviços de tradução etc.

4. É capaz de identificar os diferentes campos de especialização do tradutor e suas características específicas: produtos certificados, jurídicos, técnicos, científicos, literários, audiovisuais, de informática (localizador) etc.

5. Ele é capaz de distinguir as diferentes tarefas que o tradutor pode realizar: tradução, edição de texto, revisão e correção de textos, consultoria linguística e cultural, gerenciamento de projetos, mediação intercultural, suporte linguístico e cultural, pós-edição etc.

6. É capaz de identificar as diferentes instituições envolvidas no exercício da profissão e suas funções (associações e colégios profissionalizantes).

\section{NÍVEL DE TRADUÇÃO A2}

1. É capaz de distinguir diferentes tipos de demanda e diferentes finalidades que a tradução pode ter de acordo com os casos: cumprir o mesmo objetivo que o original (tradução equifuncional), apenas informar, acompanhar o texto original, adaptar etc. 


\section{NÍVEL DE TRADUÇÃO A1}

1. É capaz de distinguir a demanda de uma tradução e o objetivo que deve cumprir quando o objetivo não difere daquele do texto original (tradução equifuncional). 


\section{Apêndice 5: Competência de Resolução de Problemas de Tradução}

\section{NÍVEL DE TRADUÇÃO C}

1. É capaz de resolver problemas de tradução específicos de textos especializados de pelo menos um campo profissional de especialização (jurídico; econômico e financeiro; científico; técnico; literário; audiovisual; acessibilidade; localização) sem erros de sentido e respeitando as convenções da língua meta.

2. É capaz de resolver problemas decorrentes de demandas de tradução em contextos profissionais para qualquer tipo de destinatário.

3. É capaz de resolver problemas de tradução típicos do campo profissional de especialização.

[A ser desenvolvido]

\section{NIVEL DE TRADUÇÃO B2}

1. É capaz de resolver problemas de tradução de textos semiespecializados (destinados a um público não especializado) de pelo menos um campo profissional (jurídico-administrativo; econômico e financeiro; técnico; científico; editorial de cunho não literário) sem erros de sentido e respeitando as convenções da língua meta.

2. É capaz de resolver problemas decorrentes da demanda de tradução em contextos profissionais para destinatários não especializados.

3. É capaz de resolver problemas de interferência entre as duas línguas.

4. É capaz de resolver problemas básicos de discrepância temática, cultural e enciclopédica, de natureza explícita e implícita.

5. É capaz de resolver problemas de intencionalidade, relacionados a dificuldades na captação de informações do texto original (intertextualidade, pressupostos, implicaturas).

6. É capaz de resolver problemas de diferentes tipos de tradução de acordo com a demanda (tradução equifuncional, tradução informativa, adaptação etc.).

\section{NÍVEL DE TRADUÇÃO B1}

1. É capaz de resolver problemas de tradução de textos não especializados de pelo menos um campo profissional (jurídico-administrativo; econômico e financeiro; técnico; científico; editorial de cunho não literário) sem erros de sentido e respeitando as convenções da língua meta.

2. É capaz de resolver problemas decorrentes da demanda de tradução em contextos profissionais para destinatários não especializados. 
3. É capaz de resolver problemas de interferência entre as duas línguas.

4. É capaz de resolver problemas básicos de discrepância temática, cultural e enciclopédica, de natureza explícita e implícita.

5. É capaz de resolver problemas de intencionalidade, relacionados a dificuldades na captação de informações do texto original (intertextualidade, pressupostos, implicaturas).

\section{NIVEL DE TRADUÇÃO A2}

1. É capaz de resolver problemas de tradução de textos não especializados que apresentam problemas de registro (tom, estilo) de vários tipos de texto (narrativo, descritivo, expositivo, argumentativo, instrutivo) sem erros de sentido e respeitando as convenções da língua meta.

2. É capaz de resolver problemas derivados de demandas de tradução em contextos não profissionais para destinatários não especializados.

3. É capaz de aplicar os princípios metodológicos que regem a tradução para resolver problemas tradutórios, levando em consideração as várias características textuais, propósitos e destinatários.

4. É capaz de resolver problemas de interferência entre as duas línguas (convenções de escrita, léxico não especializado, morfossintaxe, textualidade) e problemas derivados de variação linguística (tom, estilo).

5. É capaz de resolver problemas de discrepância cultural e enciclopédica de natureza explícita.

6. É capaz de resolver problemas de intencionalidade, relacionados a dificuldades na captação de informações do texto original (intertextualidade, pressupostos, implicaturas).

\section{NÍVEL DE TRADUÇÃO A1}

1. É capaz de resolver problemas de tradução de textos não especializados em linguagem padrão de vários tipos textuais (narrativa, descritiva, expositiva, argumentativa, instrutiva) sem erros de sentido e respeitando as convenções da língua meta.

2. É capaz de resolver problemas derivados da demanda de tradução em contextos não profissionais para destinatários não especializados.

3. É capaz de aplicar os princípios metodológicos fundamentais que regem a tradução (objetivo comunicativo, importância de entender bem o texto fonte e de redigir bem o texto meta, importância do destinatário) para resolver problemas básicos de tradução.

4. É capaz de percorrer as diferentes etapas do desenvolvimento de uma tradução (compreensão, atualização, autorrevisão), executando as tarefas de cada uma delas para resolver problemas básicos de tradução. 
5. É capaz de resolver problemas básicos de interferência entre as duas línguas: convenções de escrita (ortografia e tipografia), léxico não especializado, morfossintaxe e textualidade (estrutura textual, progressão temática, coerência e coesão).

6. É capaz de resolver problemas de discrepância cultural e enciclopédica de natureza explícita. 